\title{
Volatile fingerprinting differentiates diverse-aged craft beers
}

\author{
Eduardo Coelho $^{\mathrm{a}, *}$, Joana Magalhães ${ }^{\mathrm{a}}$, Francisco B. Pereira ${ }^{\mathrm{b}}$, Filipe Macieira ${ }^{\mathrm{b}}$, \\ Lucília Domingues $^{\mathrm{a}}$, José M. Oliveira ${ }^{\mathrm{a}}$ \\ ${ }^{\text {a }}$ CEB - Centre of Biological Engineering, University of Minho, 4710-057, Braga, Portugal \\ ${ }^{\mathrm{b}}$ Fermentum - Engenharia das Fermentações Lda., Avenida Professor Machado Vilela, n. ${ }^{\circ}$ 147, 4730-684, Vila Verde, Portugal
}

\section{A R T I C L E I N F O}

\section{Keywords:}

Volatile fingerprinting

Wood ageing

Beer ageing

Barrel reuse

Ageing strategies

\begin{abstract}
A B S T R A C T
Beer ageing on wood is a complex and difficult to control process involving several reactions and compounds. Difficulties in understanding the underlying phenomena often lead to empirical and unpredictable processes and heterogeneous products. This work resorts to volatile fingerprinting along with multivariate analysis as tools to differentiate and highlight differences in beers derived from diverse production processes. Volatile composition of beers originating from barrel ageing processes and unaged beer were analyzed by GC-MS. The collected data was processed by principal component analysis, which allowed the evaluation of relations between samples and volatile compounds. Beers were distinguished by clusters comprising different groups of volatiles. Beer with the longest period in barrel was in the cluster with the most volatiles. Beer produced by resident barrel microbiota fermentation was characterized by presence of Brettanomyces sp. metabolites. Beer aged in barrel by a shorter time period showed characteristic content of ethyl esters and oak extractives. Beer produced in inox vat and beer fermented in barrel with pitching of $S$. cerevisiae appeared in the same cluster, relating with fermentative esters. Volatile fingerprinting was a viable approach to characterize and distinguish the analyzed beers, providing relevant information regarding the impact of production methodologies in volatile composition.
\end{abstract}

\section{Introduction}

Ageing of beverages in oak barrels is a common practice and is widely recognized for improving stability and organoleptic properties of the final product. During contact, several phenomena occur which impact beverage composition, namely the extraction of wood compounds, evaporation of beverage volatile compounds, oxidation of compounds in the beverage, and reaction between wood and beverage components (Mosedale \& Puech, 1998). Extraction of volatiles from oak barrels depends mainly on wood extractible content, contact time, cellar conditions and beverage composition (Chira \& Teissedre, 2014). Barrel usage is a crucial factor for ageing. The pool of extractable oak compounds is finite and the rate and amounts of compounds extracted diminish as the barrel is used in successive years (Wilkinson, Li, Grbin, \& Warren, 2013). Furthermore, casks also retain compounds from the beverages aged in them, due to sorption of beverages components. As shown, oak wood retains compounds from the aged beverages, which can be transferred from one beverage to another through the reuse of the cask (Coelho, Domingues, Teixeira, Oliveira, \& Tavares, 2019). Presence of lees in the cask can also take part on enhancing sensorial characteristics of alcoholic beverages, leading to higher body and aroma complexity as acknowledged in wine production (Del BarrioGalán, Pérez-Magariño, \& Ortega-Heras, 2011). Therefore, volatile composition of the aged beverage is influenced not only by the previously referred reactions occurring in the barrel but also by transference of compounds from one matrix to another, with the barrel posing as a vector for carrying such compounds and aromatic properties. Additionally, when envisaging beverages such as wine or beer, biological transformations occur during barrel ageing which furthermore modify chemical and sensory properties. Casks are often populated with microorganisms that alter significantly the beverage composition. Bacteria, such as Lactobacillus sp. and Enterobacter sp. and wild yeasts such as Brettanomyces sp., Debaryomyces sp. and Candida sp. can be found in wood and wine barrels with impact on beverage composition (Spitaels et al., 2014). Whilst mainly considered as spoilage organisms responsible for off-flavor production in wine, an increasing number of authors report that these endogenous microbes can add beneficial (or at least interesting) aromas that increase the flavor complexity of fermented beverages. On this field, Brettanomyces sp. strains are rising in importance, due to the ability to produce volatile compounds that enhance sensory properties of beer (Serra Colomer, Funch, \& Forster, 2019). Several beer styles traditionally produced by fermentation in

\footnotetext{
* Corresponding author.

E-mail address: e.coelho@ceb.uminho.pt (E. Coelho).
} 
barrel rely on typical Brettanomyces $s p$. flavors such as seen for Lambic beers (Steensels et al., 2015) and Belgian red-brown acidic ales (Snauwaert et al., 2016).

With an increasing market which strives for innovative specialty products, mainly in craft beer, barrel ageing has been applied at great extent. Variables such as wood type and origin, presence of lees, resident barrel microbiota and ageing conditions lead to a large number of possible combinations to be performed. With such extent of variables to be manipulated and taking into account the multitude of compounds involved in beer sensory characteristics, ageing results are often unpredictable lead to heterogeneous products in regard to their chemical composition and sensory characteristics. In the case of wine, which has also complex composition, fingerprinting methodologies have been applied as omics tools for the discrimination, identification and quality control of dissimilar samples (Laaks, Letzel, Schmidt, \& Jochmann, 2012) and for the investigation of the importance and effect of wine volatiles (González Álvarez, González-Barreiro, Cancho-Grande, \& Simal-Gándara, 2011).

The aim of this work was the application and evaluation of volatile fingerprinting along with multivariate analysis as a tool to discriminate and characterize differences in barrel diverse-aged beers.

\section{Materials and methods}

\subsection{Samples}

Beer samples were kindly provided by "Fermentum - Engenharia das Fermentações Lda.", originating from "Letra" craft brewery. All samples originated from the same Belgian Dark Strong Ale wort with a specific gravity of 21 in the Plato scale $\left({ }^{\circ} \mathrm{P}\right)$, leading to a beer with bitterness (IBU) of 27 and ethanol concentration, by volume, of $9 \%$. Wort was fermented with Saccharomyces cerevisiae 1762 Belgian Abbey II (Wyeast Laboratories Inc.), pitched according with the instructions of the supplier, with the exception of ab2 beer which was fermented by resident barrel microbiota. American oak barrels previously used once in Port wine ageing were kindly provided by Quinta do Portal S.A. Barrels were directly used for beer ageing without any kind of cleaning or processing. A minimum of two independent samples of each treatment were collected from the brewery, namely two for ab1, ab2, and ub and three for ab3 and ab4. For a better interpretation, information on samples, production process and ageing parameters are presented in Fig. 1.

\subsection{Chemical characterization}

\subsubsection{HPLC analysis}

Ethanol was quantified by high performance liquid chromatography (HPLC), using a Jasco chromatograph equipped with a refractive index detector (Jasco 830-RI) and an $87 \mathrm{H}$ Chrompack column $(300 \mathrm{~mm} \times 7.8 \mathrm{~mm})$ at $60^{\circ} \mathrm{C}$. A $5 \mathrm{mmol} \mathrm{L}^{-1} \mathrm{H}_{2} \mathrm{SO}_{4}$ aqueous solution was used as mobile phase at a constant flow of $0.7 \mathrm{~mL} \mathrm{~min}^{-1}$.

\subsubsection{Analysis of volatile compounds}

In a $10 \mathrm{~mL}$ culture tube (Pyrex, ref. 1636/26 MP), $8 \mathrm{~mL}$ of sample, $3.08 \mu \mathrm{g}$ of internal standard (4-nonanol), and a magnetic stir bar $(22.2 \mathrm{~mm} \times 4.8 \mathrm{~mm})$ were added.

Extraction was done by stirring the sample with $400 \mu \mathrm{L}$ of dichloromethane according to Oliveira, Faria, Sá, Barros, and Araújo (2006). After cooling at $0{ }^{\circ} \mathrm{C}$ during $15 \mathrm{~min}$, the magnetic stir bar was removed and the organic phase was separated by centrifugation (4000 $\min ^{-1}, 7 \mathrm{~min}, 4^{\circ} \mathrm{C}$ ) and the extract recovered into a vial, using a Pasteur pipette. Then, the aromatic extract was dehydrated with anhydrous sodium sulfate and placed into a new vial. Analysis of volatile compounds was performed using a gas chromatograph-mass spectrometer (GC-MS) constituted by a Varian Saturn 2000 chromatograph with a 1079 injector and an ion-trap mass spectrometer (IT-MS). Samples of

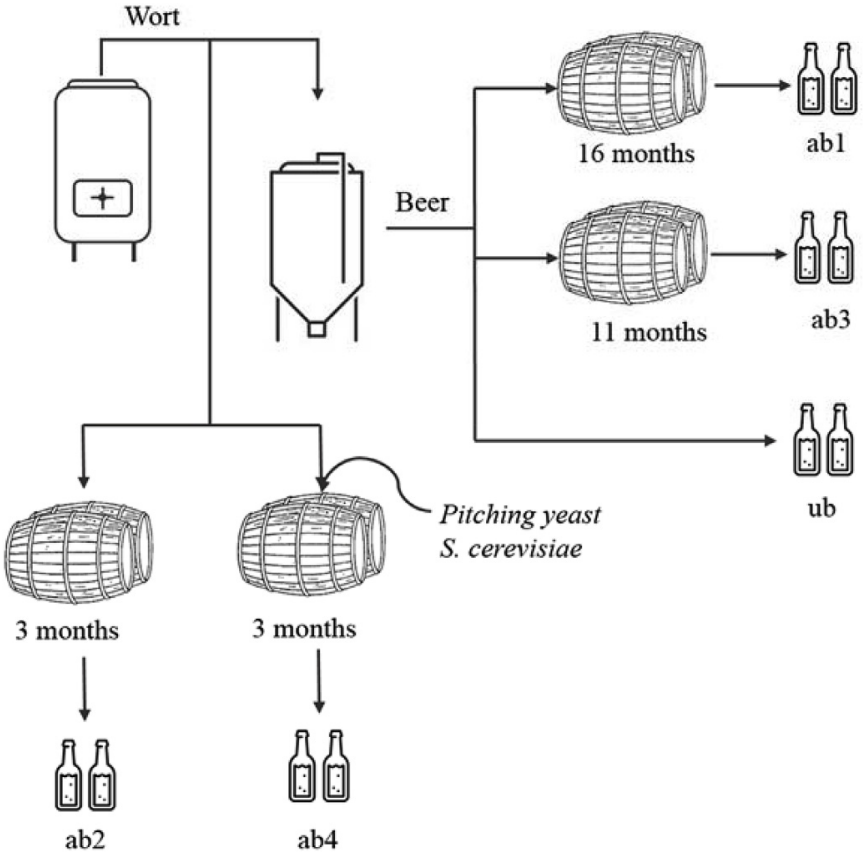

Fig. 1. Schematic representation of the strategies used for the production of the analyzed samples.

$1 \mu \mathrm{L}$ were injected in splitless mode $(30 \mathrm{~s})$ in a Sapiens-Wax MS Teknocroma column $(30 \mathrm{~m} \times 0.15 \mathrm{~mm} ; 0.15 \mu \mathrm{m}$ film thickness $)$. The temperature of the injector was held at $250^{\circ} \mathrm{C}$. The temperature of the oven was held at $60^{\circ} \mathrm{C}$, for $2 \mathrm{~min}$, then programmed to rise to $234^{\circ} \mathrm{C}$ at $3{ }^{\circ} \mathrm{C} \min ^{-1}$, raised from $234{ }^{\circ} \mathrm{C}$ to $260^{\circ} \mathrm{C}$ at $5{ }^{\circ} \mathrm{C} \mathrm{min}{ }^{-1}$ and finally held $5 \mathrm{~min}$ at $260^{\circ} \mathrm{C}$. The carrier gas was helium GHE $4 \times$ (Praxair) at a constant flow rate of $1.3 \mathrm{~mL} \mathrm{~min}{ }^{-1}$. The detector was set to electronic impact mode $(70 \mathrm{eV})$ with an acquisition range $(\mathrm{m} / \mathrm{z})$ from 35 to 300 (delay of $2.18 \mathrm{~min}$ ). The identification of volatile compounds was performed using the software Star - Chromatography Workstation version 6.9.3 (Varian), by comparing retention index with those of pure standard compounds. Volatile compounds were determined as 4-nonanol equivalents.

\subsection{Statistical analysis}

Tukey's test was conducted to determine statistically significant differences in ethanol concentration between samples, for a $95 \%$ confidence interval. Statistically significant differences in volatile compounds concentrations were assessed using a non-parametric KruskallWallis analysis for multiple comparisons and a 95\% confidence interval, using XLSTAT software (Addinsoft). In order to establish the volatile fingerprint of the analyzed samples, a PCA analysis was performed using StatSoft, Inc. (2004) STATISTICA (data analysis software), version 7.0 (www.statsoft.com). Considering the parameters of the obtained PCA, three first components were selected for the profiling of the volatile fingerprints.

\section{Results and discussion}

Analysis and characterization of beers was conducted in order to highlight differences between ageing strategies and their corresponding impact on chemical profile. As seen in Fig. 2, ethanol concentration in barrel aged beers was significantly higher when compared with the unaged beer. Firstly, contact with Port wine lees (previously aged in the same barrels) can provide additional ethanol, considering that fortified wines contain alcoholic strength by volume between $19 \%$ and $21 \%$ (Tredoux \& Silva Ferreira, 2012). As stated previously, barrels were 


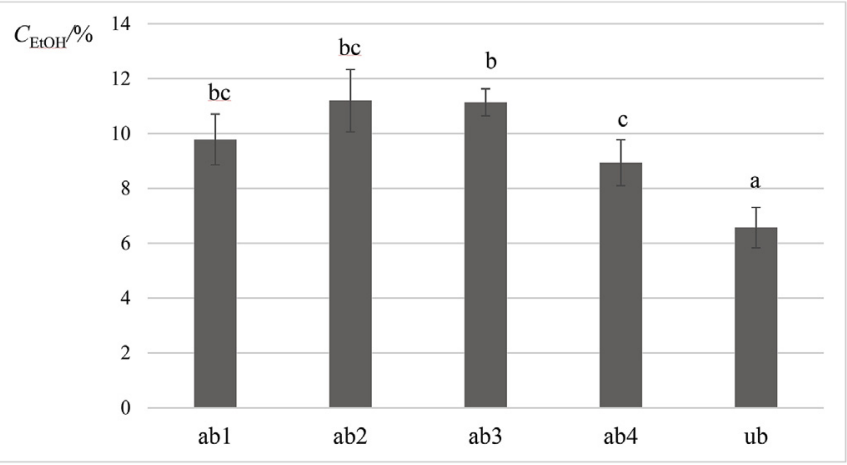

Fig. 2. Ethanol concentration $\left(C_{\mathrm{EtOH}}\right)$, by volume, in barrel aged beer and control samples. Results are shown with standard deviations of independent replicates ( $n=2$ for ab1, ab2, and $\mathrm{ub}$ and $n=3$ for ab3 and ab4).

supplied with lees and used without any prior treatment. Considering that composition and amount of lees is very difficult to measure without compromising the barrel and its application, the link between lee content and ethanol concentration cannot be directly established, but it cannot also be ruled out on the basis of the studied process. Secondly, alcoholic fermentation occurs further in the barrel, either directly from the beer wort or from residual sugars in beer. The presence of endogenous yeast in the barrel, adapted to higher ethanol concentrations, can lead to a more efficient sugar to ethanol conversion. More specifically, when comparing ab2 with ab4 samples, which were both fermented in barrel, a higher ethanol content for the ab2 sample is noticeable despite not being considered statistically significant. As referred, ab2 beer samples were obtained from barrel fermentation of wort without addition of inoculum, whereas ab4 beer samples derived from the same wort also fermented in barrel but pitched with a commercial $S$. cerevisiae yeast. Thus, fermentation in ab2 samples is exclusively attributed to resident microbiota in the barrel, whereas in ab4 the predominance of $S$. cerevisiae was imposed by pitching. In fact, sample ab2 showed higher content in Brettanomyces sp. strains, by detection with selective media, which are reported to be better adapted to high ethanol and stresses (Steensels et al., 2015). Focusing ab1 and ab3 samples, secondary fermentation could also contribute to the higher ethanol content considering that the endogenous microflora could further consume residual sugar in beer.

\subsection{Volatile compounds}

Besides increasing ethanol content, barrel ageing has a great impact on volatile composition of beers, being responsible for specific sensory traits of barrel aged beer. Volatiles were analyzed in the provided beer samples and are presented in Table 1. GC-MS analysis allowed the identification of a total of 56 volatile compounds, comprising 9 groups according to their classification.

The higher alcohols 3-methyl-1-butanol, 2-methyl-1-butanol and 2phenylethanol were the main volatile alcohols found, followed by 2methyl-1-propanol at lower proportion. These alcohols derive from sugar and amino acid metabolisms in alcoholic fermentation and can be found either in wine (Ribéreau-Gayon, Glories, Maujean, \& Dubourdieu, 2006) or in beer (Briggs, Boulton, Brookes, \& Stevens, 2004). Overall proportions of alcohols found in barrel aged beer were higher than the ones found in control beer. This can be linked either to a higher secondary alcohol production due to the more efficient ethanol conversion in barrel aged beers or due to the extraction of these compounds from wood and lees. Other alcohols, 3-ethoxy-1-propanol, Z-3hexenol, 1-pentanol and 1-butanol, for instance, were only found in barrel aged beer samples, being absent in the unaged beer. Such compounds can be present either in the barrel, by wood sorption (Coelho et al., 2019), or in lees (Liberatore, Pati, Nobile, \& Notte, 2010) and can be transferred to beer in the subsequent reutilization of the barrel. The $\mathrm{C}_{6}$-alcohol Z-3-hexenol for instance is directly related to wine considering that derives from polyunsaturated fatty acids found in grapes (Oliveira et al., 2006; Ribéreau-Gayon et al., 2006). Its exclusive presence on barrel aged samples demonstrates that characteristic wine traits were transferred to beer.

Monoterpenic alcohols, namely linalool, $\alpha$-terpineol, and $\beta$-citronellol were found in all beer samples. These monoterpenes can originate from hops used in brewing (Briggs et al., 2004) and were found in all beer samples. $\alpha$-terpineol concentration was higher in ab1 sample, when compared with the remaining, which was the beer that had a longer residence time in the barrel. $\beta$-citronellol concentration was also higher in aged beer samples, when compared to the unaged beer, with the exception of ab4 sample. These monoterpenes can derive from nerol, linalool or geraniol by different reaction mechanisms (Briggs et al., 2004; Takoi et al., 2012) which can alter their concentration during residence in barrel.

Isoamyl acetate was the main ester found in unaged beer, which is a characteristic volatile compound produced by yeast during sugar metabolism (Priest \& Stewart, 2006). In barrel aged beers a higher predominance of ethyl lactate and diethyl succinate was observed. The predominance of these esters is generally observed in wine. Ethyl esters can derive from reaction of organic acids with ethanol (Lin, Zeng, Yu, \& Sun, 2012), or in some cases are products of non $S$. cerevisiae strains metabolism, as for example ethyl lactate which derives from malolactic fermentation in wine (Ribéreau-Gayon et al., 2006). Moreover, these esters are reported as the main ones found adsorbed in wood, along with several other wine compounds (Coelho et al., 2019). The appearance and higher concentration of these wine characteristic esters in the aged beer is believed to be linked with the extraction of compounds previously adsorbed in wood to beer due to barrel reuse. Monoethyl succinate and diethyl malate are other example of this mechanism. These esters were also reported adsorbed in wood (Coelho et al., 2019) and were exclusively found in barrel aged beers along with ethyl 2methylbutyrate, ethyl 3-methylbutyrate and ethyl 3-hydroxybutyrate. Other esters typically produced by yeast during alcoholic fermentation were also found such as ethyl hexanoate and phenylethyl acetate. Besides being extracted from wood, esters found in barrel aged beers can also derive from lees, which were also found to increase the concentration of these volatiles in wine during ageing (Liberatore et al., 2010; Pérez-Serradilla \& de Castro, 2008).

Regarding volatile acids, octanoic and decanoic acids were the main found in beer samples. C4, C6, C8 and C10 acids derive from fatty acids yeast metabolism during alcoholic fermentation and can be found either in wine or in beer (Briggs et al., 2004). Only in barrel aged beers bezeneacetic and benzoic acids were found, being absent in control beer. Benzoic acid occurs in wines and is a precursor of phenolic compounds (Ribéreau-Gayon et al., 2006) and its detection in barrel aged beer reinforces the enrichment with wine traits. Overall concentration of the remaining volatile fatty acids was higher in the barrel aged beers, when compared to unaged beer. As reported for wine, the contact with lees can lead to higher volatile fatty acids concentrations (Pérez-Serradilla \& de Castro, 2008), justifying the differences observed. Another important group of compounds in regard to ageing in oak wood is lactones. Oak lactone was found in all barrel aged beers and null in the control beer, which demonstrates extraction of characteristic wood compounds from reused barrels. The ab3 samples presented the higher oak lactone content whereas the remaining barrel aged beers showed similar concentrations. This can be dependent either on residence time in barrel or more importantly from the barrel content in these extractives which are depleted during subsequent utilizations (Wilkinson et al., 2013), leading to the differences observed. Volatile phenols, were also found in higher proportions in aged beer samples, when compared to the control beer. Phenolic compounds can be extracted from wood during ageing (Le Floch, Jourdes, \& Teissedre, 2015) or derive from fermentation by the microflora in the barrel. For 


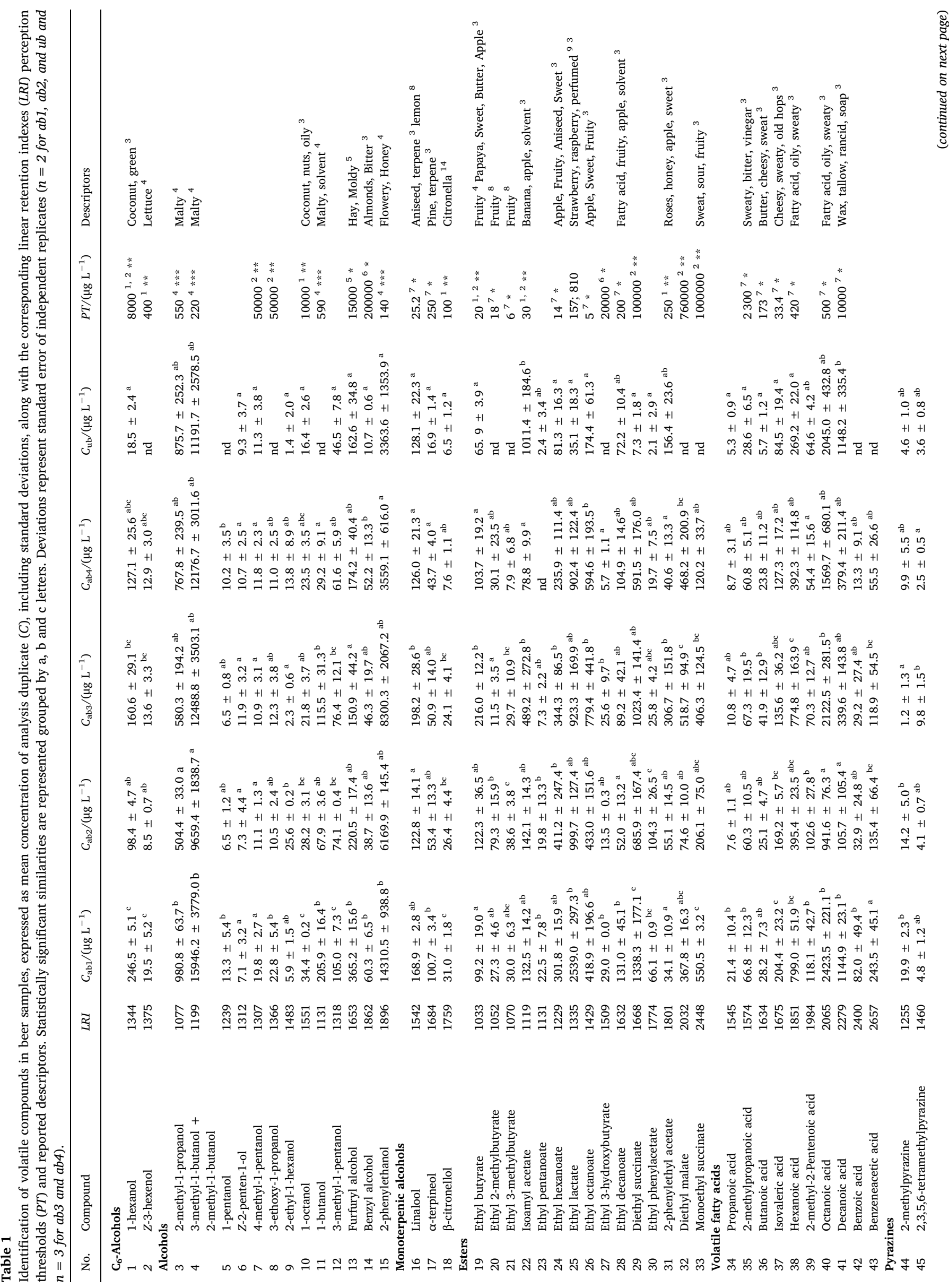




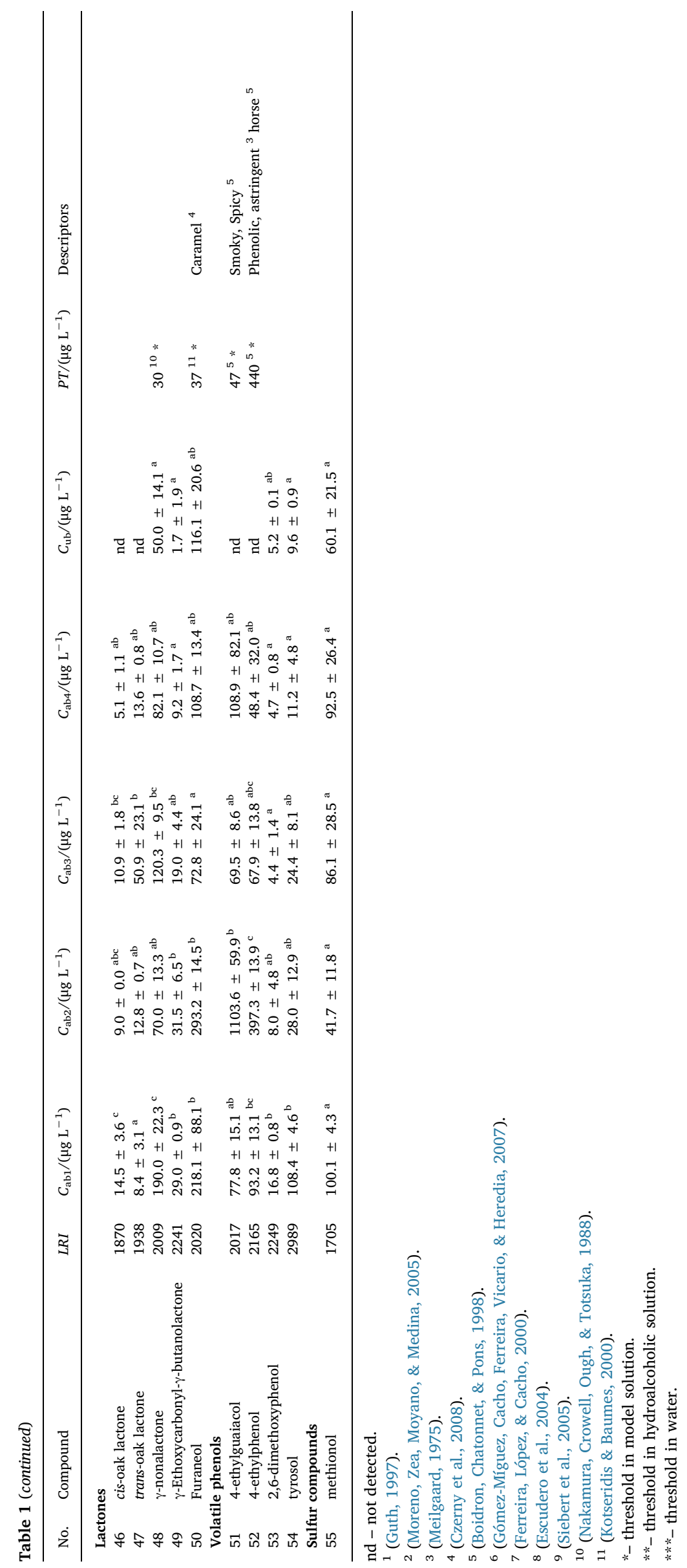


instance, 4-ethylguaiacol and 4-ethylphenol can be associated with the presence and growth of Brettanomyces/Dekkera sp. strains. These are typically associated to wine spoilage and can endure in the barrel, being found penetrating up to $8 \mathrm{~mm}$ in the wood (Suárez, Suárez-Lepe, Morata, \& Calderón, 2007). Lambic and sour beers are marked by the predominance of Brettanomyces/Dekkera sp., which are responsible for their characteristic sensory properties (Spitaels et al., 2014). The concentration of these phenolic compounds was higher in ab2, where wort was fermented by the resident barrel microbiota. High substrate availability and low stress environment favored the growth of endogenous strains present in the barrel leading to higher Brettanomyces/ Dekkera growth, detected by analysis using differential media, and consequently higher 4-ethylguaiacol and 4-ethylphenol concentrations. These volatile can also derive from Saccharomyces $s p$. metabolism (Ribéreau-Gayon et al., 2006) or be extracted from cooperage wood (Fernández de Simón, Cadahía, del Álamo, \& Nevares, 2010), which can justify their appearance in the remaining samples at lower concentrations. Tyrosol and 2,6-dimethoxyphenol were found at higher concentrations in sample ab1. Tyrosol is the fermentative product of tyrosine degradation via Ehrlich pathway (Briggs et al., 2004), and its higher concentration in ab1 when compared with the other samples was not expected. Nevertheless, considering heterogeneity of the used barrels, lees in ab1 could contribute to this difference. 2,6-dimethoxyphenol is extracted from oak wood and the higher concentration of this compound can be related to the higher ageing period of sample ab1.

\subsubsection{Volatile fingerprinting}

Considering the high number of volatiles identified, the heterogeneity in their concentrations among the samples and the overall complexity of the determinations, a principal component analysis was performed in order to assess the distinguishing traits of the different beer samples. PCA allowed the extraction of 5 principal components, explaining $84 \%$ of the sum of squares. The loadings obtained in the PCA allowed the establishment of clusters relating samples and volatile compounds, highlighting the impact of specific volatiles on overall beer composition. Loadings obtained in the PCA are available in Supplementary Table 1 . Considering that approximately $72 \%$ of the sum of squares in the PCA were explained by three of the five components extracted, these were focused for the cluster analysis. For a better interpretation of PCA data, scatterplots were outlined from the three principal components extracted, represented in Fig. 3. Fig. 4 shows a closer look on the volatiles standing closely in the cluster with each sample, taking into account the 3 extracted components.

Beer samples were located in opposite quadrants of the scatterplots, demonstrating the existence of distinctive chemical compositions. Sample ab1 appeared closely with the most volatiles, mainly in the first component. This demonstrates the richer and more diverse volatile composition of ab1 beer and goes accordingly with the previously discussed for the volatile compounds. This higher richness can be a result of its longer residence time in the barrel, during which slow occurring extraction, oxidation or condensation reactions previously discussed occurred. Fig. 4 a) demonstrates the closest volatiles to ab1 in the PCA, relatively to the 3 components. 4-methyl-1-pentanol, furfuryl alcohol, ethyl lactate, propanoic acid and tyrosol were found in the cluster of ab1 sample, and are characteristic traits of ab1 beer in comparison with the remaining. Represented in Fig. 4 b), ab2 sample was located in another cluster of the scatterplot along with several volatiles, namely ethyl-2-methylbutyrate, 2-ethyl-1-hexanol, 4-ethylguaiacol and 4-ethylphenol. Among these, proximity of ab2 samples with 4-ethylphenol and 4-ethylguaiacol clearly illustrates the impact of barrel fermentation by resident barrel microbiota in beer composition, going accordingly with the previously discussed and reinforcing the validity of the volatile fingerprint outlined. Finally, as shown in Fig. 4 c), ab3 samples were also in a separate cluster, comprising ethyl butyrate, ethyl octanoate, 2,3,5,6-tetramethylpyrazine, 2-phenylethyl
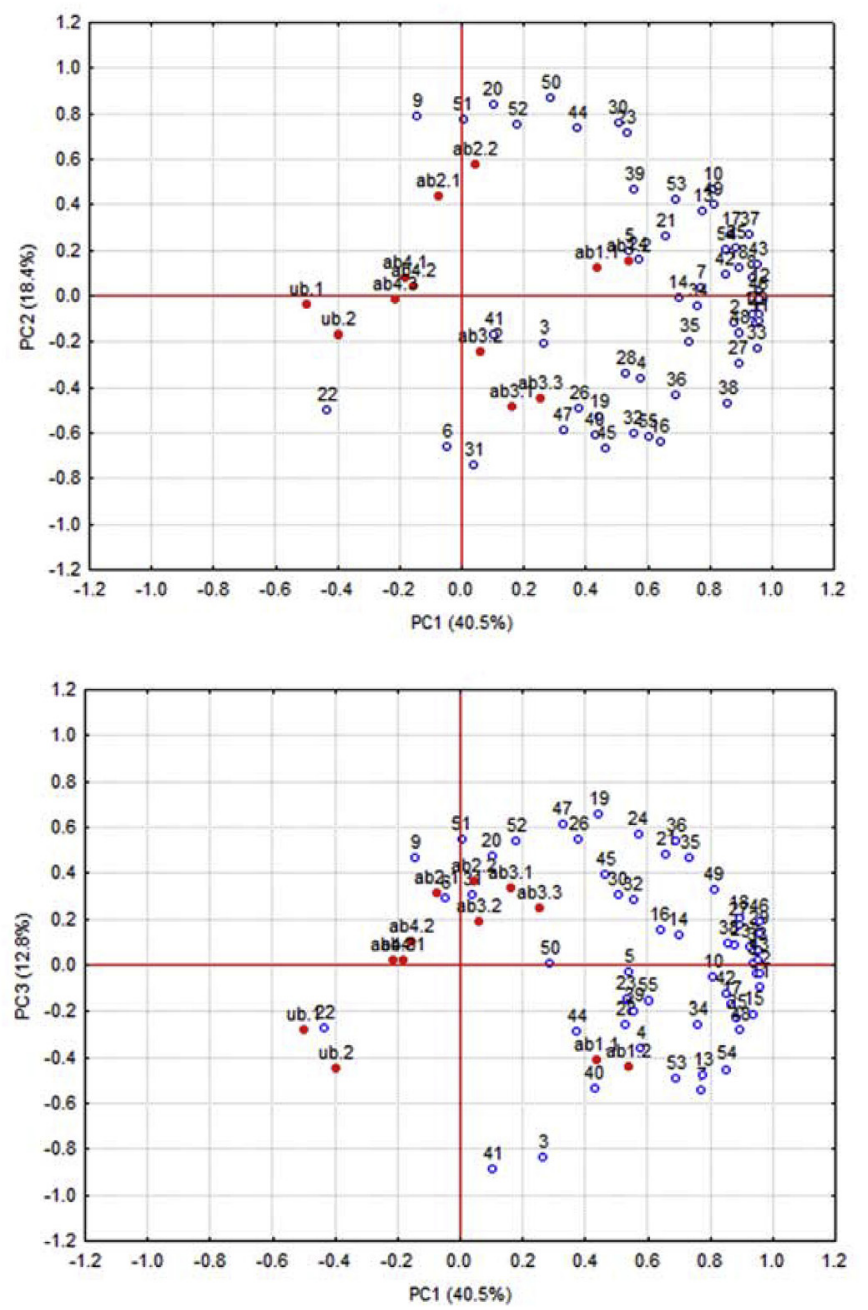

Fig. 3. Scatterplots obtained from the three extracted components of the PCA analysis representing the loadings obtained for the samples and volatile compounds (represented by numbers in Table 1).

acetate and oak lactone. Esters were the main volatiles associated with these samples, which contribute to a distinguished sweet and fruity profile of these samples. Also, oak lactone was more characteristic of ab3 samples, imparting typical oak related aroma to these beers. On the opposite side, as seen on Figs. 3 and 4 d), ab4 and ub samples appeared in an isolate cluster in the scatterplot. These samples appeared on a cluster comprising the lowest number of volatiles, being mostly associated with isoamyl acetate and Z-2-penten-1-ol. Both samples were obtained from the same wort fermented with pitched $S$. cerevisiae differing only in the vessel on which they were fermented. The appearance of these samples in the same cluster goes accordingly with their similar production process and illustrates the similarity between both. Overall volatile fingerprinting allowed the identification of tendencies from a large complex dataset, which were coherent with the differences between the studied samples. Therefore, this multivariate analysis tool can aid brewers in controlling and understanding brewing processes, shedding a light on processes which are often empirical and difficult to analyze.

\section{Conclusions}

Characterization of the barrel aged beers allowed the determination of the chemical differences between the beer samples as well as the impact of barrel reuse on beer ageing. Such was seen for the absence or pitching of $S$. cerevisiae, where wort fermented in barrel by endogenous 
a)

c)
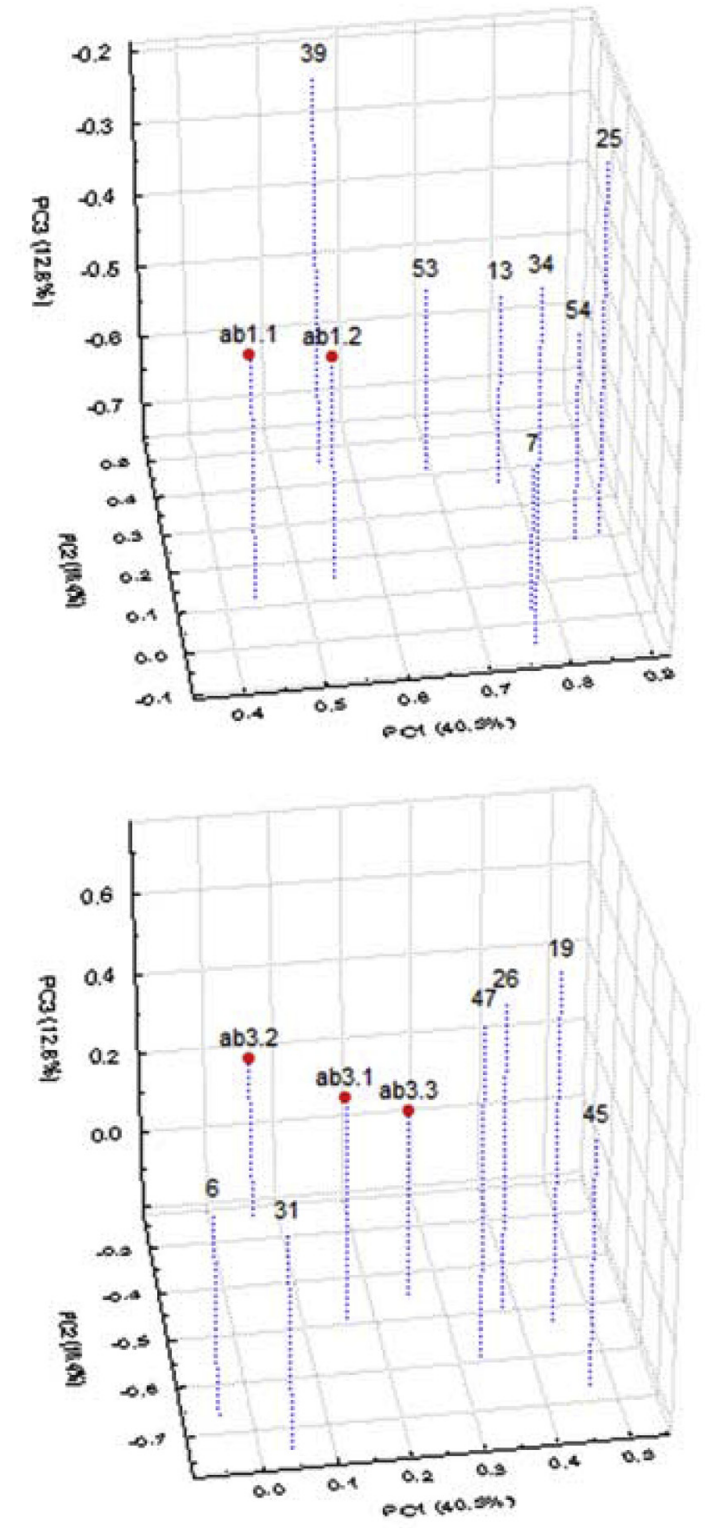

b)
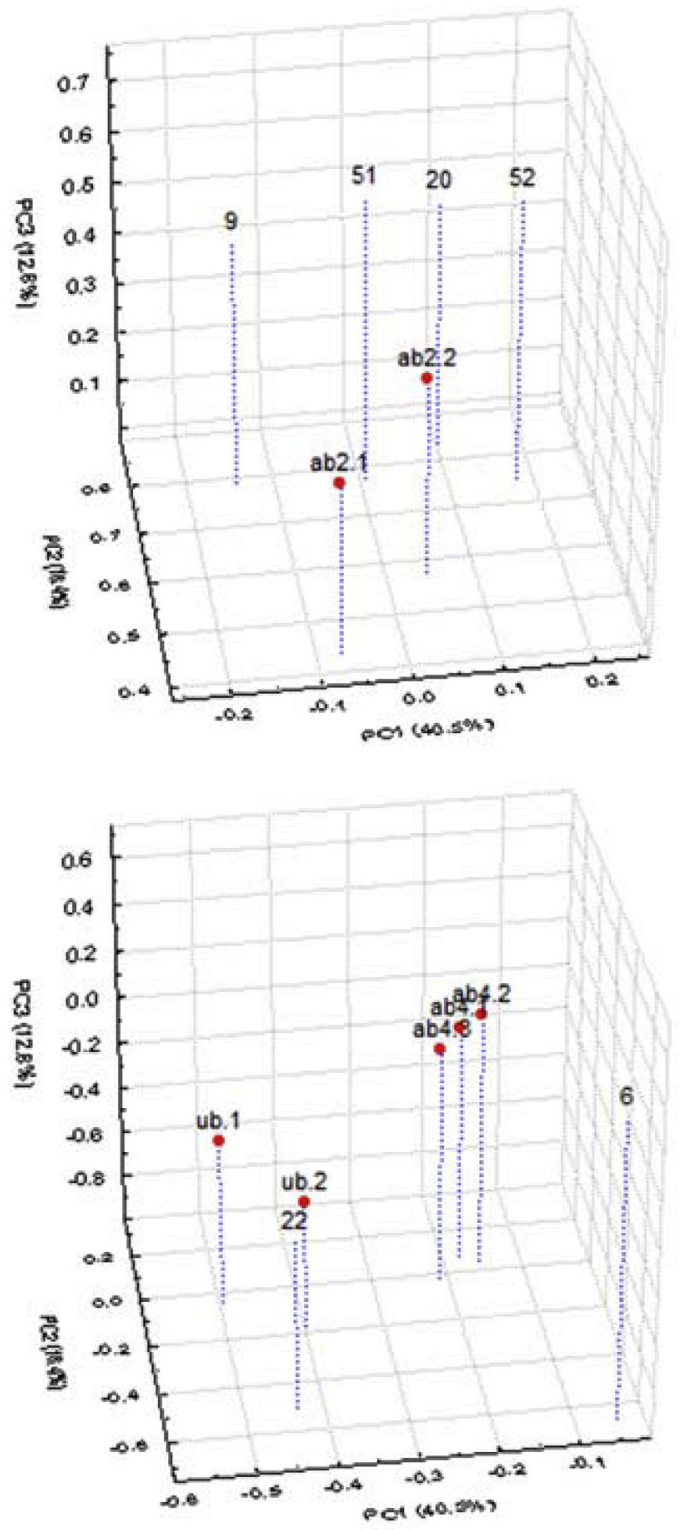

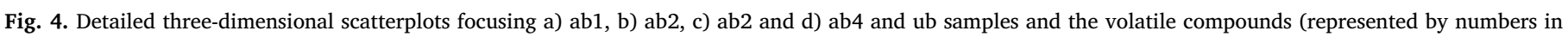
Table 1) in each cluster regarding the three extracted components.

microflora related strongly with 4-ethylphenol and 4-ethylguaiacol in the volatile fingerprint (typical Brettanomyces/Dekkera metabolites), which was less noticeable for wort also fermented in cask but with yeast inoculation. Beer aged in barrel during the longer time period appeared in the cluster comprising the higher number of volatiles in the outlined fingerprint. Beers aged in cask during a lower time period were characterized by oak lactone, a typical wood extractible. Specific wine traits were found in the barrel aged beers and absent in the control beer, demonstrating for the first time the impact of barrel reutilization in aged beer production. Volatile fingerprinting manifestly demonstrated to be appropriate for the analysis and detection of differences in beer composition, which clearly reflected the alterations in the production processes, posing as a promising tool for application in brewing and ageing processes' monitoring.

\section{Acknowledgements}

This work had funding support of the Portuguese Foundation for Science and Technology (FCT) under the scope of the strategic funding of UID/BIO/04469/2019 unit and COMPETE 2020 (POCI-01-0145-
FEDER-006684) and BioTecNorte operation (NORTE-01-0145-FEDER000004) funded by the European Regional Development Fund under the scope of Norte2020 - Programa Operacional Regional do Norte. Fermentum - Engenharia das Fermentações Lda. also participated in cofunding and supplying materials for this work. Authors would like to thank Mr. Paulo Coutinho and Quinta do Portal for supplying the oak barrels used in this work.

\section{Appendix A. Supplementary data}

Supplementary data to this article can be found online at https:// doi.org/10.1016/j.lwt.2019.03.044.

\section{References}

Boidron, J.-N., Chatonnet, P., \& Pons, M. (1998). Influence du bois sur certaines substances odorantes des vins. OENO One, 22(4), 275-294. http://doi.org/10.20870/ oeno-one.1988.22.4.1263.

Briggs, D. E., Boulton, C. A., Brookes, P. A., \& Stevens, R. (2004). Brewing: Science and practice. CRC Press.

Chira, K., \& Teissedre, P. L. (2014). Chemical and sensory evaluation of wine matured in 
oak barrel: Effect of oak species involved and toasting process. European Food Research and Technology, 240(3), 533-547. http://doi.org/10.1007/s00217-0142352-3.

Coelho, E., Domingues, L., Teixeira, J. A., Oliveira, J. M., \& Tavares, T. (2019). Understanding wine sorption by oak wood: Modeling of wine uptake and characterization of volatile compounds retention. Food Research International, 116, 249-257. http://doi.org/10.1016/J.FOODRES.2018.08.025.

Czerny, M., Christlbauer, M., Christlbauer, M., Fischer, A., Granvogl, M., Hammer, M., et al. (2008). Re-investigation on odour thresholds of key food aroma compounds and development of an aroma language based on odour qualities of defined aqueous odorant solutions. European Food Research and Technology, 228(2), 265-273. http:// doi.org/10.1007/s00217-008-0931-x.

Del Barrio-Galán, R., Pérez-Magariño, S., \& Ortega-Heras, M. (2011). Techniques for improving or replacing ageing on lees of oak aged red wines: The effects on polysaccharides and the phenolic composition. Food Chemistry, 127(2), 528-540. http:// doi.org/10.1016/j.foodchem.2011.01.035.

Escudero, A., Gogorza, B., Melús, M. A., Ortín, N., Cacho, J., \& Ferreira, V. (2004). Characterization of the aroma of a wine from Maccabeo. Key role played by compounds with low odor activity values. Journal of Agricultural and Food Chemistry, 52(11), 3516-3524. http://doi.org/10.1021/jf0353411.

Fernández de Simón, B., Cadahía, E., del Álamo, M., \& Nevares, I. (2010). Effect of size, seasoning and toasting in the volatile compounds in toasted oak wood and in a red wine treated with them. Analytica Chimica Acta, 660(1-2), 211-220. http://doi.org/ 10.1016/j.aca.2009.09.031.

Ferreira, V., López, R., \& Cacho, J. F. (2000). Quantitative determination of the odorants of young red wines from different grape varieties. Journal of the Science of Food and Agriculture, 80(11), 1659-1667. http://doi.org/10.1002/1097-0010(20000901) 80:11<1659::AID-JSFA693> 3.0.CO;2-6.

Gómez-Míguez, M. J., Cacho, J. F., Ferreira, V., Vicario, I. M., \& Heredia, F. J. (2007). Volatile components of Zalema white wines. Food Chemistry, 100(4), 1464-1473. http://doi.org/10.1016/J.FOODCHEM.2005.11.045.

González Álvarez, M., González-Barreiro, C., Cancho-Grande, B., \& Simal-Gándara, J. (2011). Relationships between Godello white wine sensory properties and its aromatic fingerprinting obtained by GC-MS. Food Chemistry, 129(3), 890-898. http:// doi.org/10.1016/j.foodchem.2011.05.040.

Guth, H. (1997). Quantitation and sensory studies of character impact odorants of different white wine varieties. Journal of Agricultural and Food Chemistry, 45(8), 3027-3032. http://doi.org/10.1021/JF970280A.

Kotseridis, Y., \& Baumes, R. (2000). Identification of impact odorants in bordeaux red grape juice, in the commercial yeast used for its fermentation, and in the produced wine. Journal of Agricultural and Food Chemistry, 48(2), 400-406. http://doi.org/10. 1021/jf990565i.

Laaks, J., Letzel, T., Schmidt, T. C., \& Jochmann, M. A. (2012). Fingerprinting of red wine by headspace solid-phase dynamic extraction of volatile constituents. Analytical and Bioanalytical Chemistry, 403(8), 2429-2436. http://doi.org/10.1007/s00216-0125909-7.

Le Floch, A., Jourdes, M., \& Teissedre, P. L. (2015). Polysaccharides and lignin from oak wood used in cooperage: Composition, interest, assays: A review. Carbohydrate Research, 417, 94-102. http://doi.org/10.1016/j.carres.2015.07.003.

Liberatore, M. T., Pati, S., Nobile, M. A. Del, \& Notte, E. La (2010). Aroma quality improvement of Chardonnay white wine by fermentation and ageing in barrique on lees. Food Research International, 43(4), 996-1002. http://doi.org/10.1016/J.FOODRES. 2010.01.007.

Lin, Z. R., Zeng, X. A., Yu, S. J., \& Sun, D. W. (2012). Enhancement of ethanol-acetic acid esterification under room temperature and non-catalytic condition via pulsed electric field application. Food and Bioprocess Technology, 5(7), 2637-2645. http://doi.org/ 10.1007/s11947-011-0678-4.

Meilgaard, M. (1975). Flavor chemistry of beer: Part II: Flavor threshold of 239 aroma volatiles. Technical Quarterly - Master Brewers Association of the Americas, 12(3), 151-168. Retrieved from http://ci.nii.ac.jp/naid/10019852641/en/.

Moreno, J. A., Zea, L., Moyano, L., \& Medina, M. (2005). Aroma compounds as markers of the changes in sherry wines subjected to biological ageing. Food Control, 16(4), 333-338. http://doi.org/10.1016/J.FOODCONT.2004.03.013.

Mosedale, J. R., \& Puech, J. L. (1998). Wood maturation of distilled beverages. Trends in Food Science and Technology, 9(3), 95-101. http://doi.org/10.1016/S0924-2244(98) 00024-7.

Nakamura, S., Crowell, E. A., Ough, C. S., \& Totsuka, A. (1988). Quantitative analysis of $\gamma$ nonalactone in wines and its threshold determination. Journal of Food Science, 53(4), 1243-1244. http://doi.org/10.1111/j.1365-2621.1988.tb13578.x.

Oliveira, J. M., Faria, M., Sá, F., Barros, F., \& Araújo, I. M. (2006). C6-alcohols as varietal markers for assessment of wine origin. Analytica Chimica Acta, 563(1-2), 300-309. http://doi.org/10.1016/J.ACA.2005.12.029.

Pérez-Serradilla, J. A., \& de Castro, M. D. L. (2008). Role of lees in wine production: A review. Food Chemistry, 111(2), 447-456. http://doi.org/10.1016/J.FOODCHEM. 2008.04.019.

Priest, F. G., \& Stewart, G. G. (2006). Handbook of brewing. CRC/Taylor \& Francis.

Ribéreau-Gayon, P., Glories, Y., Maujean, A., \& Dubourdieu, D. (2006). (2nd ed.). Handbook of enology, the chemistry of wine: Stabilization and treatmentsVol. 2John Wiley \& Sons, Inc. Handbook of Enology, The Chemistry of Wine: Stabilization and Treatments: 2nd ed http://doi.org/10.1002/0470010398.

Serra Colomer, M., Funch, B., \& Forster, J. (2019). The raise of Brettanomyces yeast species for beer production. Current Opinion in Biotechnology, 56, 30-35. http://doi. org/10.1016/j.copbio.2018.07.009.

Siebert, T. E., Smyth, H. E., Capone, D. L., Neuwöhner, C., Pardon, K. H., Skouroumounis, G. K., et al. (2005). Stable isotope dilution analysis of wine fermentation products by HS-SPME-GC-MS. Analytical and Bioanalytical Chemistry, 381(4), 937-947. http://doi. org/10.1007/s00216-004-2992-4.

Snauwaert, I., Roels, S. P., Van Nieuwerburg, F., Van Landschoot, A., De Vuyst, L., \& Vandamme, P. (2016). Microbial diversity and metabolite composition of Belgian red-brown acidic ales. International Journal of Food Microbiology, 221, 1-11. http:// doi.org/10.1016/j.ijfoodmicro.2015.12.009.

Spitaels, F., Wieme, A. D., Janssens, M., Aerts, M., Daniel, H. M., Van Landschoot, A., et al. (2014). The microbial diversity of traditional spontaneously fermented lambic beer. PLoS One, 9(4)http://doi.org/10.1371/journal.pone.0095384.

Steensels, J., Daenen, L., Malcorps, P., Derdelinckx, G., Verachtert, H., \& Verstrepen, K. J. (2015). Brettanomyces yeasts - from spoilage organisms to valuable contributors to industrial fermentations. International Journal of Food Microbiology, 206, 24-38. http://doi.org/10.1016/j.ijfoodmicro.2015.04.005.

Suárez, R., Suárez-Lepe, J. A., Morata, A., \& Calderón, F. (2007). The production of ethylphenols in wine by yeasts of the genera Brettanomyces and Dekkera: A review. Food Chemistry, 102(1), 10-21. http://doi.org/10.1016/j.foodchem.2006.03.030.

Takoi, K., Itoga, Y., Koie, K., Kosugi, T., Shimase, M., Katayama, Y., et al. (2012). The contribution of geraniol metabolism to the citrus flavour of beer: Synergy of geraniol and $\beta$-citronellol under coexistence with excess linalool. Journal of the Institute of Brewing, 116(3), 251-260. http://doi.org/10.1002/j.2050-0416.2010.tb00428.x.

Tredoux, A. G. J., \& Silva Ferreira, A. C. (2012). Fortified wines: Styles, production and flavour chemistry. Alcoholic Beverages, 159-179. Woodhead Publishing Series in Food Science, Technology and Nutrition http://doi.org/10.1533/9780857095176.2.159.

Wilkinson, K., Li, S., Grbin, P., \& Warren, P. (2013). Barrel reclamation : Everything that's old can be new again. Australian and New Zealand Grapegrower and Winemaker, (594), 70-72. 